\title{
Adequação ambiental para Ocotea odorifera (Vell.) Rohwer na floresta urbana de Curitiba, Paraná, Brasil
}

\author{
Allan Rodrigo Nunho dos Reis ${ }^{1}$ Daniela Biondi ${ }^{1}$ Bruna Kovalsyki ${ }^{1}$ Jennifer Viezzer $^{1}$ Jefferson Dias de Oliveira ${ }^{1}$ \\ ${ }^{1}$ Universidade Federal do Paraná, Av. Prefeito Lothário Meissner, 632 - Jardim Botânico, Curitiba - PR, 80210-170 \\ *Author for correspondence: allannunho@ yahoo.combr
}

Received: April 2019/ Accepted: September 2019/ Published: September 2019

\section{Resumo}

Ocotea odorifera é uma espécie arbórea que sofre pressão da urbanização na Mata Atlântica, contribuindo para o seu risco de extinção e dificultando a sua adequação ambiental. Áreas verdes protegidas urbanas, no entanto, podem atenuar esses processos por apresentar ambientes com menos impacto antrópico. O objetivo deste trabalho foi estimar a adequação ambiental para $O$. odorifera no município de Curitiba, Paraná e quantificar a sua representatividade em áreas verdes protegidas. Um mapa de distribuição potencial da espécie foi elaborado por meio do algoritmo Maxent $^{\circledR}$, utilizando-se 12 variáveis bióticas e 13 abióticas. A avaliação do desempenho do modelo foi feita pela Área Sobre a Curva (AUC). O mapa do modelo foi sobreposto a um arquivo shapefile contendo 80 áreas protegidas e reclassificado em três classes de adequação ambiental para a espécie: Alta, Média e Baixa. A área ocupada pelas classes de adequação dentro de cada área protegida foi calculada. O modelo explicou $96,3 \%$ da distribuição da espécie. A maior parte do municíp io apresenta condições pouco favoráveis à ocorrência de $O$. odorifera. A área potencialmente ocupada pela espécie em Curitiba foi de $5.132,4$ ha (11,8\% da área total do município). Somando-se as classes Alta e Média em cada área protegida, a maior área contínua com adequação ambiental está presente no Parque Tanguá, com 19,56 ha de adequação ambiental $(88,14 \%$ de sua área total). Menos de $3 \%$ da área com adequação ambiental para $O$. odorifera encontram-se em áreas verdes protegidas. Recomenda-se a criação de novas áreas protegidas voltadas para a conservação da espécie.

Palavras-chave: canela-sassafrás, biodiversidade urbana, fragmentos de habitat.

\footnotetext{
Abstract

Ocotea odorifera is a tree species that is pressured by the urbanization in the Atlantic Forest, which contributes to the increase in its extinction risk and to the decrease in its environmental suitability. Urban protected areas, however, can mitigate these problems by presenting environments with less anthropic impact. The aim of this study was to estimate the environmental suitability for $O$. odorifera in Curitiba, Paraná, and to quantify its representativeness in protected areas in the city. A potential distribution map of the species was elaborated using Maxent ${ }^{\circledR}$, with 12 biotic and 13 abiotic variables. The evaluation of the model performance was done by the Curve Area (AUC). The modeling map was superimposed on a shapefile file containing 80 protected areas and reclassified into three classes of environmental suitability for the species: High, Medium and Low. The area occupied by the adequacy classes within each protected area was calculated. The modeling explained $96.3 \%$ of the species distribution. Most of Curitiba presented conditions that are not very favorable to the occurrence of $O$. odorifera. The potential area occupied by the species in the city was $5,132.4$ ha $(11.8 \%$ of its total area). Adding the High and Middle classes in each protected area, the largest continuous area
}

with environmental suitability is present in the Tanguá Park, with 19.56 ha of environmental suitability $(88.14 \%$ of its total area). Less than $3 \%$ of the area with environmental suitability for $O$. odorifera in Curitiba are in protected areas. Thus, new protected areas for the conservation of the species should be created.

Keywords: canela-sassafrás, habitat fragments, urban biodiversity.

\section{Introdução}

A pressão antrópica sobre as áreas naturais é a maior ameaça para a conservação da biodiversidade, por provocar alterações nas características da paisagem, perda de habitat e fragmentação de ecossistemas, o que altera a adequação ambiental dos habitats para a ocorrência das espécies (Nekaris et al. 2015). Com isso, verifica-se a diminuição de populações de espécies e o consequente aumento da probabilidade de extinção.

No Brasil, a Mata Atlântica, um dos hotspots de biodiversidade mundiais, é o bioma mais afetado pelas atividades humanas, com $29 \%$ de sua área original remanescente (Myers et al. 2000; MapBiomas 2016). Dentre as 3.595 espécies da flora da Mata Atlântica avaliadas quanto ao risco de extinção, 1.544 encontram-se ameaçadas, o que corresponde a $57,82 \%$ de todas as espécies avaliadas nos seis biomas brasileiros e constantes na Lista Nacional Oficial das Espécies da Flora Brasileira Ameaçadas de Extinção, instituída pela Portaria do Ministério do Meio Ambiente (MMA) nº 443 de 17 de dezembro de 2014 (Martinelli et al. 2013; Brasil 2014).

Nesse contexto está inserida a espécie Ocotea odorifera (Vell.) Rohwer, conhecida como canela-sassafrás (Hatschbach e Ziller 1995). O. odorifera é uma espécie arbórea pertencente à família Lauraceae e endêmica do Brasil, sendo uma das indicadoras da Floresta Ombrófila Mista (FOM). Devido às pressões exercidas sobre as suas populações, a espécie encontra-se classificada como "Em Perigo" (EN), o que indica elevado risco de ser extinta no ambiente natural (International Union for Conservation of Nature and Natural Resources (IUCN); Brasil 2014).

A compreensão sobre a distribuição espacial das espécies ameaçadas de extinção é essencial para o desenvolvimento de estratégias de conservação, inclusive em cidades (Barros et al. 2011). Tendo em vista que é cada vez mais comum que o tamanho das áreas urbanizadas exceda o tamanho total das áreas protegidas para conservação (Dearborn e Kark 2010), as áreas protegidas presentes nas cidades tornam-se ainda mais importantes para a proteção das espécies.

No entanto, pouco se conhece sobre a adequação ambiental para $O$. odorifera no contexto urbano e a importância deste fator para a delimitação de áreas verdes protegidas para a conservação da espécie, uma vez que comumente se considera as áreas urbanas apenas como uma categoria de uso do solo.

O objetivo do presente trabalho foi estimar a adequação 
ambiental para $O$. odorifera no município de Curitiba, Paraná e quantificar a sua representatividade dentro de áreas verdes protegidas da cidade.

\section{Material e Métodos \\ Área de estudo}

A área de estudo compreende todo o município de Curitiba (Figura 1), localizado na região Sul do Brasil, dentro dos limites da Mata Atlântica. O município possui 43.527 ha de área total, com extensão norte-sul de $33 \mathrm{~km}$ e leste-oeste de $21 \mathrm{~km}$ e altitude média de 934,6 metros (Instituto de Pesquisa e Planejamento Urbano de Curitiba (IPPUC) 2015). A cidade é subdividida em 75 bairros e 10 unidades administrativas, chamadas de regionais e o seu marco zero situa-se na Praça Tiradentes $\left(25^{\circ} 25^{\prime} 46,89754^{\prime \prime}\right.$ S e 49¹6'16,56011" W) (IPPUC 2015).

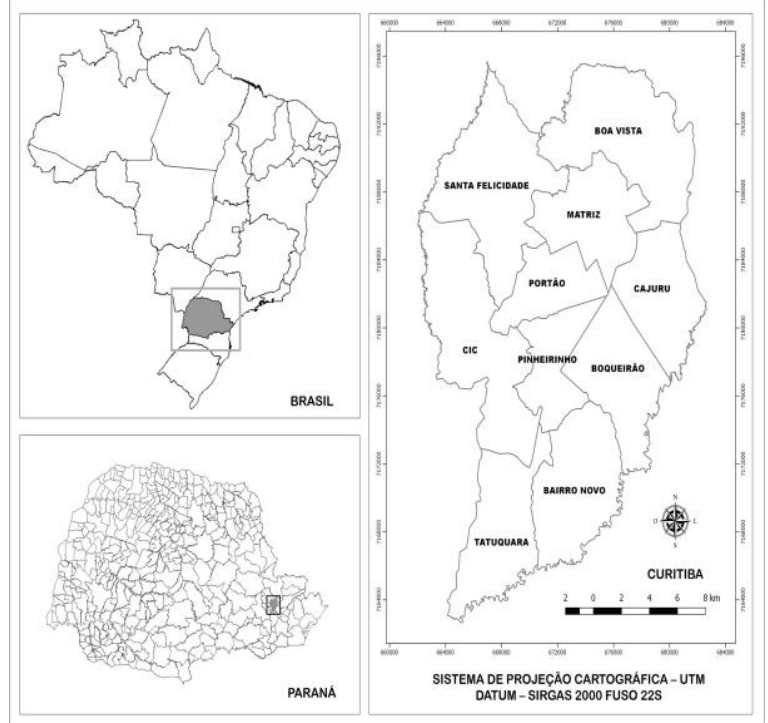

Figura 1 - Localização do município de Curitiba noEstado do Paraná e divisão administrativa da cidade.

Segundo a classificação climática de Köeppen-Geiger, o clima de Curitiba é do tipo $\mathrm{Cfb}$ (subtropical úmido e mesotérmico), com verões amenos e invernos moderados a rigorosos (IPPUC 2015). A temperatura média anual da região é de $17,4^{\circ} \mathrm{C}$, variando nas médias de 21,1 a $35^{\circ} \mathrm{C}$ nos meses mais quentes e de 13,4 até $-2{ }^{\circ} \mathrm{C}$ nos meses mais frios em média e a pluviosidade média do município é de 1.486,5 $\mathrm{mm} / \mathrm{ano}$ (Wrege et al. 2012).

A vegetação original de Curitiba apresentava formações vegetais com espécies características de FOM (Montana e Aluvial) e campos naturais (Selusniaki e Acra 2010). Nas regiões de FOM, localizadas ao norte do município, ocorriam principalmente as espécies arbóreas Araucaria angustifolia (Bertol.) Kuntze (araucária), Ocotea porosa (Nees \& Mart.) Barroso (imbuia) e $O$. odorifera (Roderjan et al. 2002). No restante do município havia a predominância de campos limpos, constituídos principalmente por espécies da família Poaceae, entremeados por pequenos fragmentos florestais onde predominavam A. angustifolia, $O$. porosa e $O$. odorifera, sendo as duas últimas formadoras de densos subbosques, caracterizando a fitofisionomia da região (Klein e Hatschbach 1962; Roderjan et al. 2002).

Atualmente, a floresta urbana do município corresponde a $43,69 \%$ da cidade, sendo composta por $34,70 \%$ de floresta urbana particular, inserida dentro das quadras e $8,98 \%$ de floresta urbana pública, considerando-se o arruamento, as áreas verdes e os corpos hídricos (Grise et al. 2016a). Dessa cobertura vegetacional, 4,99\% da área total de Curitiba correspondem à vegetação presente nas ruas, 3,23\% correspondem à vegetação presente em áreas verdes e $0,76 \%$ são compostas pela vegetação presente no entorno dos corpos hídricos.

Curitiba possui 21 Reservas Particulares do Patrimônio Natural Municipal (RPPNMs); 9 Bosques de Conservação da Biodiversidade Urbana (BCBUs); 1 Estação Ecológica (EE); 16 bosques; 27 parques; 1 jardim botânico, 1 Reserva da Vida Silvestre (RVS) e 1.033 áreas verdes representadas por largos e praças, além de outras categorias que só existem no município, como jardinetes, eixos de animação, jardins ambientais e núcleos ambientais, totalizando mais de 1.100 áreas verdes (IPPUC 2018).

\section{Procedimentos metodológicos}

Um dos métodos mais utilizados para estimar a distribuição espacial de espécies é a Modelagem de Distribuição Potencial de Espécies (MDPE). Os modelos de distribuição potencial representam, por meio da cartografia, a adequação de um espaço geográfico para a presença de determinada espécie, com base em variáveis que indiquem as condições ambientais do local onde foi encontrada, prevendo assim, as áreas com possíveis novas ocorrências (Phillips et al. 2004; Mateo et al. 2011; Shcheglovitova e Anderson 2013). Desse modo, a MDPE representa a adequação do habitat para as espécies (Khanum et al. 2013).

A MDPE pode fornecer subsídios à identificação dos fatores que atuam na presença das espécies e à avaliação da representatividade de áreas adequadas dentro de áreas protegidas (Alexandre et al. 2013). Com isso, a MDPE pode indicar lacunas de proteção para as espécies ameaçadas (Alexandre et al. 2013); apresentar locais potenciais para a restauração de suas populações (Hemery et al. 2016) e subsidiar projetos de implantação e gestão de áreas protegidas com base nestas espécies (Ferrer-Sánchez e RodríguezEstrella 2016).

Para a determinação da adequação ambiental nos habitats de $O$. odorifera em Curitiba, um mapa de distribuição potencial da espécie no município foi elaborado por meio do algoritmo Maxent $^{\circledR}$ (Maximum Entropy) (Phillips et al. 2004), versão 3.4.1 de 2017. Como variáveis bióticas, foram utilizados 12 pontos de ocorrência confirmada da espécie no município de Curitiba e 13 variáveis ambientais (variáveis abióticas). Essas variáveis foram escolhidas por serem consideradas pertinentes à autoecologia da espécie (Figueiredo et al. 2015), e por fornecerem suporte a sua adequação ambiental. Foram avaliadas as seguintes variáveis ambientais: altitude, curvatura horizontal do terreno, curvatura vertical do terreno, declividade, fitogeografia, forma do terreno, geologia, orientação do terreno, pedologia, precipitação média anual, relevo sombreado, temperatura máxima e temperatura mínima. A avaliação do desempenho do modelo foi feita pela Área Sobre a Curva (AUC) (MoreraChacón 2015).

O mapa gerado pelo modelo de distribuição potencial foi sobreposto a um arquivo shapefile fornecido pelo IPPUC, com arquivos vetoriais datados de julho de 2018, contendo a delimitação de seis tipologias de áreas verdes protegidas, sendo 48 áreas parques e bosques; 21 RPPNMs; nove BCBUs, uma EE e um RVS, totalizando 80 áreas protegidas.

Essas tipologias de área verde protegida foram escolhidas por possuírem as maiores áreas de fragmentos de vegetação remanescente do município (Grise et al. 2016b); por oferecerem maiores possibilidades de conservação da espécie em relação às áreas particulares comuns, uma vez que já se encontram com os seus usos consolidados regidos por 
dos Reis et al.

legislações específicas (Curitiba 2000; 2015) e por apresentarem, em geral, menos impactos antrópicos. No entanto, como existem outras tipologias de áreas verdes protegidas no município e que não se enquadram nos referidos requisitos, optou-se pelo termo Áreas Verdes Protegidas Selecionadas (AVPS).

O mapa original fornecido pelo Maxent ${ }^{\circledR}$, contendo 14 classes de probabilidade de ocorrência da espécie e a delimitação das áreas protegidas foi, então, reclassificado em três classes, sendo: Alta, Média e Baixa adequação ambiental para $O$. odorifera, com base nos intervalos das classes originais, a cada, aproximadamente, $33 \%$ de probabilidade de ocorrência da espécie, com adaptação das metodologias propostas por Morera-Chacón (2015) e Coelho et al. (2016). Essa etapa visou a melhor quantificação das áreas potenciais para a presença da espécie, e posterior determinação das áreas prioritárias para a sua conservação. Para isso, foi realizada uma classificação supervisionada no software ArcGis ${ }^{\circledR} 10.3$.

Posteriormente, realizou-se um recorte da paisagem representada pelas maiores probabilidades de ocorrência de $O$. odorifera, visando quantificar a área representada pela adequação ambiental para a espécie dentro de cada AVPS. O recorte da paisagem foi feito com base nos limites das regionais administrativas de Curitiba estabelecida pelo IPPUC (2018).

A área ocupada pelas classes de probabilidade de ocorrência dentro de cada área protegida foi calculada de acordo com Morera-Chacón (2015). Essa quantificação é útil pois dentro de uma AVPS podem ocorrer diferenças nas características ambientais, principalmente as topográficas.

\section{Resultados e Discussão}

O modelo gerado pelo Maxent ${ }^{\circledR}$ apresentou desempenho de 0,963 , em uma escala que varia de 0 a 1 , indicando que o modelo gerado explica $96,3 \%$ da distribuição da espécie na área de estudo.

Verificou-se que a região centro-norte de Curitiba, que compreende as regionais Boa Vista, Matriz, Santa Felicidade e Cajuru, possui as maiores probabilidades de ocorrência de O. odorifera, apresentando as melhores classes de adequação ambiental para a espécie, com valores próximos a 1.

A reclassificação da adequação ambiental, demonstrada por meio do modelo de distribuição potencial, indicou que a maior parte do município de Curitiba apresenta condições pouco favoráveis à ocorrência de $O$. odorifera, correspondendo a pouco menos de $90 \%$ de sua área total, conforme apresentado na tabela 1 .

Tabela 1 - Classes de adequação ambiental para O. odorifera no município de Curitiba, Paraná.

\begin{tabular}{ccc}
\hline Classe & Área total (ha) & Área relativa (\%) \\
\hline Alta & $1.766,8$ & 4,1 \\
Média & $3.365,6$ & 7,7 \\
Baixa & $38.322,3$ & 88,2 \\
\hline
\end{tabular}

Esse resultado contrapõe o encontrado por Martins (2016) quanto à distribuição potencial de $O$. odorifera para a porção do Brasil constituída pela Mata Atlântica. O referido estudo indicou que parte da região do município de Curitiba deve ser considerada uma das áreas prioritárias para a conservação da espécie, devido à maior adequação ambiental que fornece a sua autoecologia, com probabilidade de ocorrência superior a $0,75(75 \%)$. Essa diferença nos resultados deve-se à escala espacial utilizada nos dois estudos. Murphy e Lovett-Doust (2007) explicam que quando os modelos são aplicados em áreas de grande extensão geográfica, ocorre baixo nível de detalhamento, além de não ser considerada a variação regional nas condições ambientais e suas interaç̃os e o comportamento das espécies, o que reduz sua precisão.

Com isso, torna-se importante a estimativa da distribuição potencial das espécies em áreas menores, como de municípios e Unidades de Conservação (UCs), visando o melhor detalhamento das condições do habitat para o estabelecimento e conservação de espécies. Segundo Kerr et al. (2011), a escala de trabalho é irrelevante para a MDPE, porém a resolução espacial dos dados pode influenciar os resultados de estudos para a definição de áreas prioritárias à conservação.

A área potencialmente ocupada por $O$. odorifera em Curitiba é de 5.132,4 ha, o que corresponde a $11,8 \%$ da área total do município (Figura 2). O restante da área apresenta condições inferiores de adequação ambiental por constituir relevo menos acidentado e com maiores possibilidades de encharcamento do solo. Tais fatores podem constituir barreiras biogeográficas ao estabelecimento da espécie, uma vez que $O$. odorifera possui preferência por altitudes e declividades elevadas, além de solos das classes dos Latossolos e Cambissolos, presentes principalmente na porção norte do município (Yang et al. 2013; Martins, 2016).

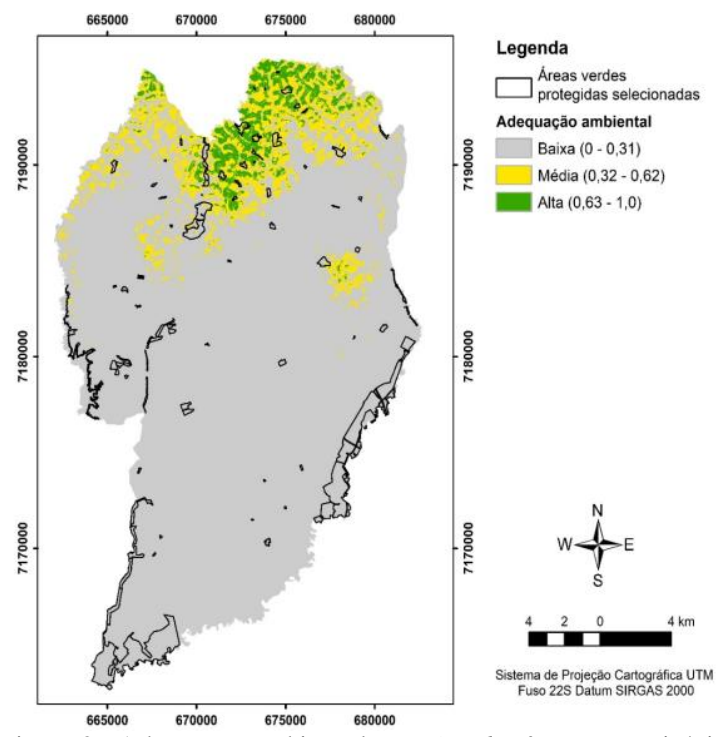

Figura 2 - Adequação ambientalpara $O$. odorifera no município de Curitiba, Paraná.

Foram contabilizadas 51 áreas protegidas selecionadas na região centro-norte de Curitiba, sendo que 59,61\%, representadas por 31 áreas, apresentam algum grau relevante de adequação ambiental para $O$. odorifera, ou seja, correspondem às classes Alta e Média e são, portanto, as mais pertinentes a sua conservação (Figura 3). 


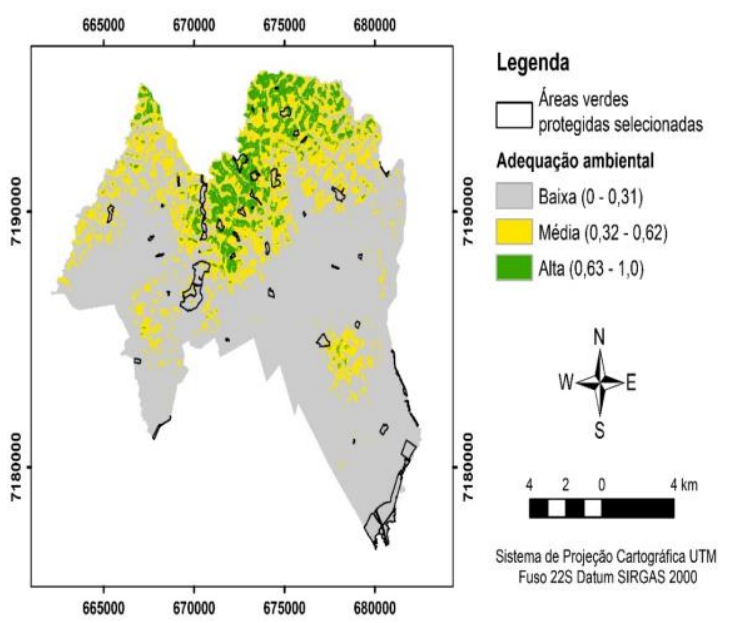

Figura 3 - Classes de adequação ambiental para $O$. odorifera na porção centro-norte de Curitiba, Paraná.

Essas 31 áreas protegidas são representadas por 12 parques, 10 RPPNMs, 8 bosques e 1 BCBU. A tabela 4 indica as áreas de adequação ambiental presentes nas AVPSs da região centro-norte de Curitiba. A área do município na região centro-norte com Alta adequação ambiental para $O$. odorifera correspondeu a $1.763,3$ ha, sendo que 36,39 ha estão contidos em 21 áreas protegidas. A área com adequação Média recobriu 3.311,8 ha, com 95,73 ha presentes no interior de 31 AVPSs. Além disso, ainda se verificou que a classe Baixa se sobressaiu nessa região do município, correspondendo a 74,04\% da área total da região centro-norte.

O local com a maior área de adequação ambiental Alta para a espécie foi o Parque Tanguá, com 12,09 ha, o que corresponde a $54,50 \%$ de sua área total. Na sequência estão o Parque das Pedreiras, com 5,69 ha (55,82\% de sua área total), e o Parque Municipal da Barreirinha, com uma área de adequação ambiental de 4,74 ha (35,85\% de sua área total).

Para a classe de adequação ambiental Média, as maiores áreas estão no Parque Bariguii, com 13,86 ha, o que representa $10,33 \%$ de sua área; no Parque São Lourenço, com 12,95 ha, correspondendo a $56,38 \%$ de sua área total e no Bosque Zaninelli, com 5,99 ha, correspondente a $87,51 \%$ da área total.

Somando-se as classes Alta e Média em cada área protegida, verifica-se que as maiores áreas contínuas de adequação ambiental estão presentes nos parques Tanguá, que apresenta uma área com adequação ambiental de 19,56 ha, cerca de $88,14 \%$ de sua área total, seguido pelos parques Barigüi e São Lourenço, com 15,9 ha e 15,75 ha, os quais correspondem a $11,84 \%$ e $68,55 \%$ de suas áreas totais, respectivamente.

Dentre as RPPNMs, a Geronasso, a maior do município, possui a maior área de adequação nas classes Alta e Média, com 1,61 ha (classe Alta), que ocupam 37,44\% de sua área total e 1,88 ha (classe Média). A segunda maior área de adequação ambiental nessa tipologia de área verde encontrase na RPPNM Airumã, com 2,42 ha de adequação ambiental, cuja classe Alta recobre $37,53 \%$ de sua área total e a classe Média, 49,27\%. Em terceiro lugar está a RPPNM Vô M antino e Amélia, cuja área de adequação ambiental corresponde a 1,71 ha, representando $72,98 \%$ de sua área na classe Alta $\mathrm{e}$ $19,57 \%$ na classe Média.

A região centro-norte de Curitiba contém a maior quantidade de áreas verdes protegidas do município (Grise et al. 2016a; 2016b), podendo fornecer melhores condições para a proteção dos atuais indivíduos de $O$. odorifera. Além disso, essas áreas protegidas podem ser utilizadas para incrementar a regeneração natural da espécie e plantios de reintrodução.

Ainda existem áreas, principalmente particulares, que podem ser transformadas em UCs na região centro-norte. São áreas propícias a plantios de reintrodução da espécie, uma vez que, segundo Grise et al. (2016a), essas regiões periféricas de Curitiba, incluindo-se a norte, possuem ainda algumas áreas com vegetação remanescente. Acrescenta-se a isso os resultados de um mapeamento que indicou a existência de aproximadamente 1.000 propriedades particulares com remanescentes florestais distribuídas em Curitiba, com potencial para serem transformadas em RPPNMs (Pinto et al. 2017).

De acordo com a tabela 2, a área de adequação ambiental Alta apresentou a maior proporção dentro das áreas verdes protegidas selecionadas. Por outro lado, menos de $1 \%$ das áreas com adequação Média estão contidas nas AVPSs. Com isso, considerando que 132,12 ha favoráveis à ocorrência de $O$. odorifera encontram-se dentro de AVPSs, estas áreas assumem um papel essencial para a conservação da espécie.

Tabela 2 - Classes de adequação ambiental para O. odorifera na região centro-norte do município de Curitiba, Paraná.

\begin{tabular}{lclll}
\hline Classe & $\begin{array}{l}\text { Área } \\
\text { total (ha) }\end{array}$ & $\begin{array}{l}\text { Área total } \\
\text { relativa(\%) }\end{array}$ & $\begin{array}{l}\text { Área em } \\
\text { áreas } \\
\text { protegidas } \\
\text { (ha) }\end{array}$ & $\begin{array}{l}\text { Área } \\
\text { relativa em } \\
\text { áreas } \\
\text { protegidas } \\
(\%)\end{array}$ \\
\hline Alta & $1.763,3$ & 9 & 36,39 & 2,063 \\
Média & $3.311,8$ & 16,9 & 95,73 & 0,028 \\
Baixa & $14.475,2$ & 74 & 403,8 & 0,027 \\
\hline
\end{tabular}

Esse resultado se deve ao fato de a espécie não ter preferência pelas partes mais baixas do terreno, próximo aos cursos d'água (Pottker et al. 2016), contrapondo-se à localização das áreas protegidas públicas presentes em Curitiba, onde normalmente se prioriza a hidrografia do local. No primeiro Plano Diretor de Curitiba, elaborado no ano de 1966, foi recomendado a instalação de parques e bosques ao longo dos cursos d'água, com a finalidade principal de reter água das chuvas, que causavam enchentes frequentes na época; de prevenir a ocupação desordenada dos mananciais e de servir como espaços de lazer para a população, com a criação de lagos, originando diversas reservas florestais nas cotas mais baixas, dando início à política de implantação de áreas verdes no município (Castelnou 2006; Sakata 2011).

No caso das RPPNMs, os proprietários são obrigados a manter, eternamente, a proteção da área, com vistas à conservação da diversidade biológica (Lima e Franco 2014). De modo que não existe a necessidade direta de conservação de corpos hídricos para a sua criação, em contraste com o que ocorre na maioria dos parques e bosques do município. Por isso, considerando tais características entre as áreas verdes protegidas e privadas, as reservas particulares tornam-se mais relevantes à conservação de $O$. odorifera .

Embora em escalas espaciais pequenas, como no meio urbano, existam fragmentos de habitat com pequenas dimensões, em comparação com outros ambientes menos alterados, estes podem apresentar condições ambientais favoráveis à ocorrência de determinadas espécies. Isso se deve às características presentes no interior de fragmentos, os quais também exercem influência relevante ao estabelecimento das espécies, principalmente daquelas com características autoecológicas mais específicas, como $O$. odorifera.

Com isso, $O$. odorifera, por sua importância ecológica e sua vulnerabilidade à extinção, pode ser considerada como uma espécie-chave, devido ao impacto ocorrido em sua região de 
dos Reis et al.

ocorrência natural. Outro aspecto se refere à importância econômica da espécie com relação à extração do óleo essencial safrol de suas partes, utilizado em produtos de limpeza, higiene e farmacêuticos (Dalmaso et al., 2013). Portanto, reforça-se a existência de diferentes interesses que permeiam a conservação de $O$. odorifera.

Desse modo, a criação de áreas protegidas como os Bosques de Conservação da Biodiversidade Urbana (BCBUs), já existentes em Curitiba, pode ser uma ferramenta importante para a conservação desta e de outras espécies características da Floresta Ombrófila Mista. Essa afirmação condiz com a principal finalidade desse modelo de unidade de conservação, que é a de proteger espécies da Floresta Ombrófila Mista, conforme a Lei Municipal n 15.047/2017 (Curitiba 2017).

Desse modo, considera-se que todos os fragmentos classificados como habitat disponível para uma determinada espécie representam habitats adequados, pois a qualidade interna dos fragmentos pode ser tão ou mais importante do que seu tamanho ou sua configuração espacial, devido às variações ambientais, principalmente topo-edáficas (García 2011). Além disso, segundo Dalmaso et al. (2013), também ocorrem oscilações entre a mortalidade e o recrutamento de indivíduos de $O$. odorifera devido, principalmente, às condições bióticas, como a competição intraespecífica e a densidade de plantas no local. Assim, tanto a adequação ambiental quanto a autoecologia de $O$. odorifera, podem ser consideradas para a conservação da espécie.

\section{Conclusão}

Uma pequena parte do território de Curitiba, localizada na porção centro-norte do município, apresenta condições ambientais favoráveis ao estabelecimento de $O$. odorifera, tanto de forma natural quanto por meio de plantios da espécie.

Menos de 3\% da área de adequação ambiental correspondente às classes Alta e Média para a espécie encontra-se dentro das áreas verdes mais pertinentes a sua conservação. Com isso, estas áreas assumem um papel essencial para a conservação da espécie.

Recomenda-se a criação de RPPNMs e de BCBUs na região mais relevante à ocorrência de $O$. odorifera, levando em consideração a proximidade de corpos hídricos, um dos requisitos que desfavorece a ocorrência da espécie.

São necessários estudos detalhados quanto ao processo de dispersão de $O$. odorifera, especificamente no meio urbano, a fim de se obter melhor esclarecimento quanto à influência das características dos fragmentos de habitat sobre o seu estabelecimento e como a sua conservação se relaciona com a de outras espécies.

\section{Agradecimentos}

À Coordenação de Aperfeiçoamento de Pessoal de Nível Superior (CAPES) pela concessão da bolsa para a realização do estudo.

\section{Referências}

Alexandre, BR, Lorini ML, Grelle CEV (2013) Modelagem preditiva de distribuição de espécies ameaçadas de extinção: um panorama das pesquisas. Oecologia Australis, 17(4):483-508.

Brasil (2014) Ministério do Meio Ambiente. Portaria n ${ }^{\circ} 443$, de 17 de dezembro de 2014. Reconhece como espécies da flora brasileira ameaçadas de extinção aquelas constantes da "Lista Nacional Oficial de Espécies da Flora Ameaçadas de Extinção". Ministério do Meio Ambiente. Brasília, 17 dez. 2014. Disponível em: <http://www.icmbio. gov.br/cep
3\%A7\%C3\%A3o.pdf>. Acesso em: 14 ago. 2018.

Barros, FSM, Siqueira MF, Costa DP (2012) Modeling the potential geographic distribution of five species of Metzgeria Raddi in Brazil, aiming at their conservation. The Bryologist, 115(2):341-349.

Castelnou, AMN (2006) Parques urbanos de Curitiba: de espaços de lazer a objetos de consumo. Cadernos de Arquitetura e Urbanismo, 13(14):53-73.

Coelho G, Carvalho LMT, Gomide, LR (2016) Modelagem preditiva de distribuição de espécies pioneiras no Estado de Minas Gerais. Pesquisa Agropecuária Brasileira, 51(3):207-214, 2016

Curitiba (2000) Lei n. 9804, de 03 de janeiro de 2000. Cria o sistema de unidades de conservação do município de Curitiba e estabelece critérios e procedimentos para implantação de novas unidades de conservação, Curitiba, 2000. Disponível em: <http://multimidia.curitiba.pr.gov.br/ 2010/00084669.pdf>. Acesso em: 15 ago. 2018.

Curitiba (2015) Lei n. 14.587, de 14 de janeiro de 2015. Reestrutura o programa das Reservas Particulares do Patrimônio Natural Municipal - RPPNM no município de Curitiba, revoga as leis $\mathrm{n}^{\circ} 12.080$, de 19 de dezembro de 2006 e lei $n^{\circ} 13.899$, de 9 de dezembro de 2011, Curitiba, 2015. Disponível em: <http://multimidia.curitiba.pr.gov.br/ 2015/00171164.pdf>. Acesso em: 15 ago. 2018.

Curitiba (2017) Lei $\mathrm{n}^{\circ} 15.047$, de 25 de agosto de 2017. Inclui inciso $\mathrm{X}$ ao art. $3^{\circ}$ da Lei $\mathrm{n}^{\circ}$ 9.804, de 3 de janeiro de 2000, que Cria o Sistema de Unidades de Conservação do Município de Curitiba e estabelece critérios e procedimentos para implantação de novas unidades de conservação. Disponível em: <https://leismunicipais.com.b r/a/pr/c/curitiba/lei-ordinaria/2017/1504/15047/lei-ordinari a-n-15047-2017-inclui-inciso-x-ao-art-3-da-lei-n-9804-de3-de-janeiro-de-2000-que-cria-o-sistema-de-unidades-deconservacao-do-municipio-de-curitiba-e-estabelece-criteri os-e-procedimentos-para-implantacao-de-novas-unidadesde-conservacao>. Acesso em: 15 ago. 2018.

Dalmaso CA, Inoue MT, Oliveira-Filho PC, Marcelino VR (2013) Padrões espaciais na regeneração de Ocotea odorifera na Floresta Nacional de Irati, PR. Floresta, 43(2):301-312.

Dearborn DC, Kark S (2010) Motivations for conserving urban biodiversity. Conservation Biology, 24(2):432-440.

Ferrer-Sánchez Y, Rodríguez-Estrella R (2016) How rare species conservation management can be strengthened with the use of ecological niche modelling: the case for endangered endemic Gundlach's Hawk and Cuban BlackHawk. Global Ecology and Conservation, 5:88-99.

Figueiredo SDM, Venticique E, Figueiredo EO, Ferreira EJL (2015) Predição da distribuição de espécies florestais usando variáveis topográficas e de índice de vegetação no leste do Acre, Brasil. Acta Amazonica, 45(2):167-174.

García D (2011) Efectos biológicos de la fragmentación de hábitats: nuevas aproximaciones para resolver un viejo problema. Ecosistemas, 20(2):1-10. 
dos Reis et al.

Grise MM, Biondi D, Araki H (2016a) A floresta urbana da cidade de Curitiba, PR. Floresta, 4(4):425-438. doi: 10.5380/rf.v46i3.42212

Grise MM, Biondi D, Araki H (2016b) Distribuição espacial e cobertura de vegetação das tipologias de áreas verdes de Curitiba, PR. Floresta e Ambiente, 23(4):498-510. doi: http://dx.doi.org/10.1590/2179-8087.127715

Hatschbach GG, Ziller SR (1995) Lista vermelha de plantas ameaçadas de extinção no Estado do Paraná. Curitiba: SEMA/GTZ. 139p.

Hemery LG, Marion SR, Romsos CG, Kurapov AL, Henkel SK (2016) Ecological niche and species distribution modelling of sea stars along the Pacific Northwest continental shelf. Diversity and Distributions, 22(12):0114. doi: $10.1111 /$ ddi. 12490

International Union for Conservation of Nature and Natural Resources - IUCN (2012). IUCN Red list categories and criteria. 2nd Edition. 3.1. Gland: IUCN. 32p.

Instituto de Pesquisa e Planejamento Urbano de Curitiba IPPUC (2015). Nossa Curitiba: perfil físico-territorial e socioeconômico da cidade de Curitiba, 2015. Curitiba: IPPUC. 36p.

Instituto de Pesquisa e Planejamento Urbano de Curitiba IPPUC (2018) Arquivos shapefile de áreas verdes de Curitiba. Disponível em: <http://ippuc.org.br/geodownload s/geo.htm>. Acesso em: 02 ago. 2018.

Kerr JT, Kulkarni M, Algar A (2011) Integrating theory and predictive modeling for conservation research. In: Drew CA, Wiersma YF, Huettmann F (ed) Predictive species and habitat modeling in landscape ecology: concepts and applications. New York: Springer. p.9-28.

Khanum R, Mumtaza AS, Kumar S (2013). Predicting impacts of climate change on medicinal asclepiads of Pakistan using Maxent modeling. Acta Oecologica, 49:2331.

Klein RM, Hatschbach G (1962) Fitofisionomia e notas sobre a vegetação para acompanhar a planta fitogeográfica do município de Curitiba e arredores (Paraná). Boletim da Universidade do Paraná. Geografia Física. Curitiba, (4).

Lima PCAD, Franco JLDA (2014) As RPPNs como estratégia para a conservação da biodiversidade: o caso da Chapada dos Veadeiros. Sociedade \& Natureza, 26(1):113125 .

Martinelli G, Valente ASM, Maurenza D, Kutschenko DC, Judice DM, Silva DS et al. (2013) Avaliações de risco de extinção de espécies da flora brasileira. In: Martinelli G, Moraes MA (org) Livro vermelho da flora do Brasil. Rio de Janeiro: Andrea Jakobsson: Instituto de Pesquisas Jardim Botânico do Rio de Janeiro. p.60-103.

Martins EM (2016) Conservação de Ocotea catharinensis, $O$. odorifera e O. porosa: espécies de Lauraceae ameaçadas de extinção. Tese, Instituto de Pesquisas Jardim Botânico do Rio de Janeiro / Escola Nacional de Botânica Tropical. $154 \mathrm{p}$.
Morera-Chacón BH (2015) Distribución potencial de Musa velutina (Musaceae) en las áreas silvestres protegidas de Costa Rica. Revista Geográfica de América Central, 54:171-181.

Murphy HT, Lovett-Doust J (2007) Accounting for regional niche variation in habitat suitability models. Oikos, 116:99110. doi: 10.1111/j.2006.0030-1299.15050.x

Myers N, Mittermeier RA, Mittermeier CG, Fonseca GA, Kent J (2000) Biodiversity hotspots for conservation priorities. Nature, 403(6772):853-858.

Nekaris KAI, Arnell AP, Svensson MS (2015) Selecting a conservation surrogate species for small fragmented habitats using ecological niche modelling. Animals, 5(1):27-40.

Phillips S, Dudík M, Schapire R (2004) A maximum entropy approach to species distribution modeling. Proceedings of the Twenty-first International Conference on Machine Learning. p.655-662.

Pinto LP, Hirota M, Guimarães E, Fonseca M, Martinez DI, Takahashi CK (2017) Unidades de Conservação Municipais da Mata Atlântica. São Paulo: SOSMA. 104p.

Pottker GS, Oliveira-Filho PC, Figueiredo-Filho A, Dalmaso CA (2016) Padrão espacial de espécies florestais: estudo de caso com Ocotea odorifera (Vell.) Rohwer. Ciência Florestal, 26(4):1097-1106.

Roderjan CV, Galvão F, Kuniyoshi YS, Hatschbach GG (2002) As unidades fitogeográficas do Estado do Paraná. Ciência \& Ambiente, 24(1):75-92.

MapBiomas (2016) Bioma Mata Atlântica: Relatório Final da coleção 1. Disponível em: <https://s3.amazonaws.com/map biomas-costage/Base+de+dados/Metodologia/RelatorioCo lecao1_mata_atlantica_abril2016_v4.pdf. Acesso em: 18 fev. 2018 .

Sakata FG (2011) Paisagismo urbano: requalificação e criação de imagens. São Paulo: EdUSP. 272p.

Selusniaki M, Acra LA (2010) O componente arbóreoarbustivo de um remanescente de Floresta com Araucária no município de Curitiba, Paraná. Floresta, 40:593-602.

Shcheglovitova M, Anderson RP (2013) Estimating optimal complexity for ecological niche models: a jackknife approach for species with small sample sizes. Ecological Modelling, 269:9-17.

Wrege MS, Steinmetz S, Reisser Júnior C, Almeida IR (2012) Atlas climático da região Sul do Brasil: Estados do Paraná, Santa Catarina e Rio Grande do Sul. Brasília: EMBRAPA 332p.

Yang XQ, Kushwaha SPS, Saran S, Xu J, Roy PS (2013) Maxent modeling for predicting the potential distribution of medicinal plant, Justicia adhatoda L. in Lesser Himalay an foothills. Ecological Engineering, 51:83-87. 